\title{
MEDIA PEMBELAJARAN SRAPBOOK PADA HIMPAUDI MAGELANG UTARA
}

\author{
Paramita Nuraini*1, Subiyanto ${ }^{2}$, \\ 1,2Universitas Muhammadiyah Magelang; Jl. Tidar No 21 Magelang, telp/fax (0293) \\ 56126/(0293)361004 \\ ${ }^{3}$ Program Studi Bimbingan Konseling, Fakultas Keguruan Ilmu Pendidikan, Universitas \\ Muhammadiyah Magelang \\ e-mail: paramitanuraini@ummgl.ac.id
}

\begin{abstract}
Community service activities in the form of assistance in pembutan scrapbook learning media at HIMPAUDI Magelang Utara. This activity aims to provide knowledge and skills in developing learning media. The ability to develop learning media is expected to improve the quality of PAUD teachers in Northern Magelang. The target in this community service activity is PAUD educators in North Magelang. Assistance in developing learning media in the form of scrapbook is done by lecture, demonstration and training method. Lecture method was conducted to explain the concept of innovative learning media in early childhood. Methods of demonstration are used to show that the use of scrapbook learning media can be an innovative learning medium in early childhood. While the training method is used to practice PAUD educators in Magelang City to make Scrapbook as an innovative learning media in early childhood. Benefits obtained by participants of this activity include obtaining understanding, knowledge and can create innovative learning media in the form of Scrapbook so that expected all PAUD North Magelang educators become qualified educators
\end{abstract}

Keywords_-Instructional Media, Scrapbook

\begin{abstract}
Abstrak
Kegiatan pengabdian masyarakat berupa pendampingan dalam pembutan media pembelajaran scrapbook pada HIMPAUDI Magelang Utara. Kegiatan ini bertujuan untuk memberikan pengetahuan dan ketrampilan dalam mengembangkan media pembelajaran. Kemampuan mengembangkan media pembelajran diharapkan dapat meningkatkan kualitas pendidik PAUD Magelang Utara. Sasaran dalam kegiatan pengabdian masyarakt ini adalah pendidik PAUD di Magelang Utara. Pendampingan dalam mengembangkan media pembelajran berupa scrapbook dilakukan dengan metode ceramah, demonstrasi dan pelatihan. Metode ceramah dilakukan untuk menjelaskan konsep media pembelajran yang inovatif di PAUD. Metode demonstrasi digunakan untuk menunjukkan bahwa penggunaan media pembelajran scrapbook dapat menjadi media pembelajran inovatif di PAUD. Sedangkan metode pelatihan digunakan untuk mempraktikkan pendidik PAUD Kota Magelang untuk membuat Scrapbook sebagai media pembelajran inovatif di PAUD. Manfaat yang diperoleh peserta dari kegiatan ini antara lain memperoleh pemahamna, pengetahuan dan dapat membuat media pembelajaran inovatif berupa Scrapbook sehingga diharapkan semua pendidik PAUD Magelang Utara menjadi pendidik yang berkualitas.
\end{abstract}

Kata Kunci - Media pembelajaran Scrapbook

\section{PENDAHULUAN}

Peran media dalam pembelajaran khususnya dalam pendidikan anak usia dini semakin penting artinya mengingat perkembangan anak pada saat itu berada pada masa berfikir konkrit. Oleh karena itu salah satu prinsip pendidikan untuk anak usia dini harus berdasarkan realita artinya bahwa anak diharapkan dapat mempelajari sesuatu secara nyata. Dengan demikian dalam pendidikan untuk anak usia dini harus menggunakan sesuatu yang memungkinkan anak dapat 
belajar secara konkrit. Prinsip tersebut mengisyaratkan perlunya digunakan media sebagai saluran penyampai pesan-pesan pendidikan untuk anak usia dini. Seorang guru pada saat menyajikan informasi kepada anak usia dini harus menggunakan media agar informasi tersebut dapat diterima atau diserap anak dengan baik dan pada akhirnya diharapkan terjadi perubahan-perubahan perilaku berupa kemampuan-kemampuan dalam hal pengetahuan, sikap dan ketrampilannya.

Permasalahan yang terjadi dalam proses pembelajaran pada PAUD wilayah kota Magelang adalah kurangnya kreatifitas dan inovasi pendidik dalam memberikan media pembelajaran, pendidik mengajar dengan metode ceramah, apabila menggunakan media hanya media itu itu saja belum ada inovasi dalam memberikan pembelajaran dikelas maupun luar kelas. hal ini memiliki dampak bagi para siswa PAUD yakni kurangnya motivasi belajar karena media yang monoton dan tidak inovatif yang dilakukan oleh pendidik. Terlihat banyak siswa yang lebih asik bermain dengan teman maupun dengan mainannya daripada memperhatikan guru waktu memberikan pembelajaran dikelas.

Banyak penelitian yang sudah dilakukan terkait dengan media inovasi dalam pembelajaran di PAUD menggunakan Film, video namun hal ini memberikan dampak yang negatif salah satunya adalah siswa menjadi kecanduan menonton video dan merusak kesehatan mata.

Dari permasalahan diatas penulis mempunyai solusi yakni pembelajran inovatif dan kratif pada PAUD menggunakan media scrapbook. scrapbook adalah seni menempel foto atau gambar di media kertas, dan menghiasnya hingga menjadi karya kreatif. Media ini dapat dilakukan sesuai tema yang akan di berikan oleh siswa dan media ini sangat mudah buat dan murah.

\section{METODE}

Ada tiga metode yang diterapkan dalam pelatihan ini, yaitu metode penyuluhan, pelatihan, dan pendampingan . Metode penyuluhan diterapkan dalam mengenal pembelajaran yang kratif inovatif pada guru PAUD. Metode pelatihan digunakan untuk melatih atau mendemonstrasikan metode srcapbook dalam pembelajaran PAUD. Pendampingan dilakukan peneliti untuk memantau sejauh mana pembelajaran menggunakan media srcpbook pada PAUD yang dilakukan oleh guru PAUD.

Adapun langkah yang telah ditempuh dalam kegiatan pengabdian ini mencakup beberapa tahap berikut ini.

\section{Persiapan}

Tahap persiapan merupakan tahap awal sebelum pelaksanaan PKU. Dalam tahap ini ada beberapa hal yang dilakukan, yakni koordinasi internal, dilakukan oleh Tim untuk merencanakan pelaksanaan secara konseptual, operasional, serta job description masingmasing anggota, penentuan dan recruitment peserta pelatihan.

\section{Pelaksanaan}

Pelaksanaan pelatihan Tahap ini merupakan tahap pelatihan yang diberikan kepada para orang tua. Pelaksanaan pelatihan ini mencakup beberapa hal berikut.

\section{a. Penyajian Materi}

Materi yang disajikan terkait dengan pembelajaran yang kratif inovatif pada PAUD. Penyajian ini diploting dalam 6 hari tatap muka. Penyajian materi adalah tim pengabdian sendiri disesuaikan dengan bidang keahlian masing-masing. Materi yang tersajikan sebanyak 4 (empat) bahasan yang masing-masing disajikan oleh anggota Tim Pengabdi. 


\section{b. Penugasan Praktik}

Pendidik PAUD diberikan pelatihan berupa pembuatan scrapbook sebagai media pembelajaran yang kreatif dan inovatif .

\section{Refleksi dan Diskusi}

Di akhir kegiatan peserta dan Tim melakukan refleksi hasil pelatihan dan para peserta juga memberikan evaluasi akan pelatihan ini. Selain itu juga mendiskusikan kendala dan hambatan yang dihadapi dalam kegiatan ini. Orang tua diberikan kesempatan mengkomparasikan pembelajaran yang dlakukan guru PAUD sebelum ikut pelatihan dan sesudah ikut pelatihan.

\section{HASIL DAN PEMBAHASAN}

Adapun beberapa kegiatan pengabdian kepada masyarakat yang telah dilaksanakan pada HIMPAUDI MAgelang Utara :

a. Penyampaian Materi

Penyampaian materi terkait "Media Pembelajaran Scrapbook bagi PAUD" dilaksanakan pada tanggal 27 Januari 2017, kegiatan ini dilaksanakn di PAUD Bahkti Husada Magelang dengan jumlah peserta 30 peserta yakni pendidik PAUD Magelang Utara. Penyampaian materi dilakukan untuk memberikan pemahamna dan pengetahuan bagi peserta tentang pentingnya pendidik dalam mengembangkan media pembelajran yang inovatif terhadap peserta didik khususnya PAUD, pengembangan media pembelajran harus disesuikan dengan karakteristik peserta didik, salah satu media pembalajaran inovatif yang sesuai pada PAUD yakni penggunaan srcpbook. Dalam kegiatan ini responden diberikan pre test mengenai pemahaman peserta tentang media pembelajaran di PAUD .

b. Penugasan Praktik

Penugasan praktik dilakukan pada tanggal 10 Februari dihadiri 30 pendidik PAUD Magelang Utara, kegiatan ini dilakukan dengan melibatkan mahasiswa dalam mendampingi pembuatan media pembelajaran srcpbook.

c. Pendampingan

Pendampingan dilakukan untuk memantau sejauh mana pembelajaran menggunakan media srcpbook di PAUD yang dilakukan oleh HIMPAUDI Magelang Utara.

d. Penutup

Akhir dari kegiatan pelatihan ditutup dengan pengisisan angket post tes bagaimana tingkat kreativitas Dengan Media Pembelajaran Srcpbook pada HIMPAUDI Magelang Utara setelah diadakan kegiatan pengabdian masyarakat tersebut. Pengisian kuisioner oleh peserta kegiatan. Kuisioner ini digunakan untuk mendapatkan respon peserta serta evaluasi dari kegiatan yang telah dilakukan.

Analisis terhadap hasil tes menunjukkan perubahan yang sangat besar dalam pemahaman peserta dalam media pembelajaran di PAUD. Tes menunjukkan konsep media pembelajran di PAUD informasi hasil pre test menunjukkan hanya 7 peserta dari 30 peserta $(23 \%)$ peserta memiliki pemahaman tentang konsep media pembelajaran di PAUD sedangkan hasil post test mencapai 25 peserta $(83,3 \%)$. tes tentang penggunaan scrapbook sebagai media pembelajran di PAUD menunjukkan tidak ada satu orang pun ( $0 \%$ ) yang menggunakan scrapbook sebagai media pembelajran di PAUD hasil posttest menunjukkan $100 \%$ peserta menggunakan media scrapbook seebagai media pembelajran di PAUD.

Berdasarkan hasil evaluasi terhadap pelaksanaan pengabdian masyarakat ini menunjukan sebagian besar peserta menyatakan materi yang disampaikan sesuai dengan kebutuhan mereka di lapangan dan media scrapbook dapat menjadi alternative media pembelajran inovatif di PAUD. 


\section{KESIMPULAN}

Dari kegiatan pengabdian kepada masyarakat ini, dapat ditarik kesimpulan sebagai berikut

a. Media pembelajaran Scrapbook dapat dijadikan alternative media pembelajaran kreatif pada PAUD.

b. Berdasarkan evaluasi dengan pengisian kuisioner, maka dapat diperoleh hasil adanya peningkatam kreatifitas dengan media pembelajaran Scrapbook pada HIMPAUDI Magelang Utara .

\section{SARAN}

Adapun beberapa saran dari kegiatan pengabdian masyarakat ini diantaranya:

a. Perlunya pengembangan media pembelajran yang inovatif terhadap pendidik PAUD.

b. Dalam mengembangngkan pembelajran yang inovatif pada PAUD hendaknya disesuaikan dengan karakter peserta didik.

\section{UCAPAN TRIMAKSIH}

Kegiatan Pengabdian Masyarakat ini didanai oleh LP3M Universitas Muhammadiyah Magelang.

\section{DAFTAR PUSTAKA}

[1] Aqib, Zainal , 2009, Belajar dan Pembelajaran di Taman Kanak-Kanak. Bandung, CV Yrama.

[2] Azhar Arsyad, 2002. Media Pembelajaran. Jakarta : Raja Grapindo Persada.

[3]Hurlock, 1999. Psikologi Perkembangan (terjemahan), dalam Susanto 2011, Perkembangan Anak Usia Dini. Jakarta ; Kencana Prenada Media Group. 